\title{
Reliability Assessment of Multiple Quantum Well Avalanche Photodiodes
}

\author{
Ilgu Yun, Hicham M. Menkana*, Yang Wang, Ismail H. Oguzman, Jen Kolnik, \\ Kevin F. Brennan, Gary S. May, Christopher J. Summer", and Brent K. Wagner" \\ School of Electrical and Computer Engineering \\ - Ceorgia Tech Research Institute \\ Georgia Instiute of Technology \\ Atlinta, GA $30332-0250$
}

\begin{abstract}
The reliability of doped-barrier AGaAs/GaAs multi-quantum well avalanche photodiodes fabricated by MBE is investigated vis accelerated life tests. Dark current and breakdown volage were the parameters monitored. The cetivation energy of the degradation mechanism and median device lifetime were determined. Device failure probability as a function of time was compured using the lognormal model. Analysis using the electron-beam induced current (EBIC) method revealed the degradation to be caused by ionic impurities or contamination in the pas. sivation layer.
\end{abstract}

\subsection{Introduction}

Multiple quantum well avalanche photodiodes - (APDs) are of interest as an ultrn-low noise image capture mechanism for high definition systems [1]. In this application, the image capture stage must have sufficient optical gain to ensble very sensitive light delection, but at the same time, the gain derived during detection must not contribute additional noise. Properly designed APDs can meet these specifications, but the long-term performance of these devices under conditions approximating actual operation is of critical importance in determining system reliability.

In this paper, accelerated life resting of NGaAs/GaAs multiple quantum well (MQW) APDs has been conducted with the objective of extimating long-term device reliability. Since en increase in durk current results in a reduction of the APD signal-to-noise ratio [2] and breakdown voltage determines the operntional voltage range of the device, these two fuctors represent the most ensitive indicator of the characicristic degradation in these devices. Thus, dark current and breakdown voluge were the parameters monitored in this study. The degradation in these parumeters was investigated via high temperature stornge tests ind accelented life tests, and the results of these tests were uscd to estimate device lifetime by assuning on Arthenius-type temperature dependence [3]. Using the median device lifetime and its standard deviation as parameters, the failure probability of each device as a Sunction of time was computed [4].

Following device stressing, endysis was conducted 10 determine the failure mechenism. It has been previously reported that the APD failure modes are primarily surface failures, wach as electrode failure tue to the interfacial reaction between metal and emiconductor or oxide contamination in the semiconductor surface [5-6]. High temperature operation will sccelente surface failures by increasing the mobility of the contuminmts. Polential fillure mechnnisms were evaluated using scenning electron microscopy (SEM) and the electron-beam induced ourrent (EBIC) method [7]. Based on this analysis, a failure mechanism of ionic impurities of contamination in the passivation layer at the junction prrimeter is proposed.

\subsection{Accelerated Life Texting}

\subsection{Device Structure and Fabrication}

The device structure of the photodiodes inverti. gated is shown in Figure 1. The devices were grown by molecular beam epitaxy (MBE) at the Georgia Tech Research Institute. The basic stoucture was that of a pi-n diode where the intrinsic region was composed of the MQW superlatice structure. The $p$ and $n$ contact layers are $1.0 \mathrm{\mu m}$ and $15 \mathrm{\mu m}$ thick, respectively, and doped at a level of $10^{18} \mathrm{~cm}^{-3}$ [8]. The $1-3 \mu \mathrm{m}$ thick GaAs/AlGaAs superlattice region consists of 25 periods of $200 \AA$ GaAs quantum wells sepanted by $800 \AA$ AIGaAs burier hyers. One complete period consists of - 300 X high-field AKaAs region doped at $3 \times 10^{18} \mathrm{~cm}^{-3}$, the $200 \&$ undoped GaAs layer, and a $500 \AA$ undoped AGaAs layer.

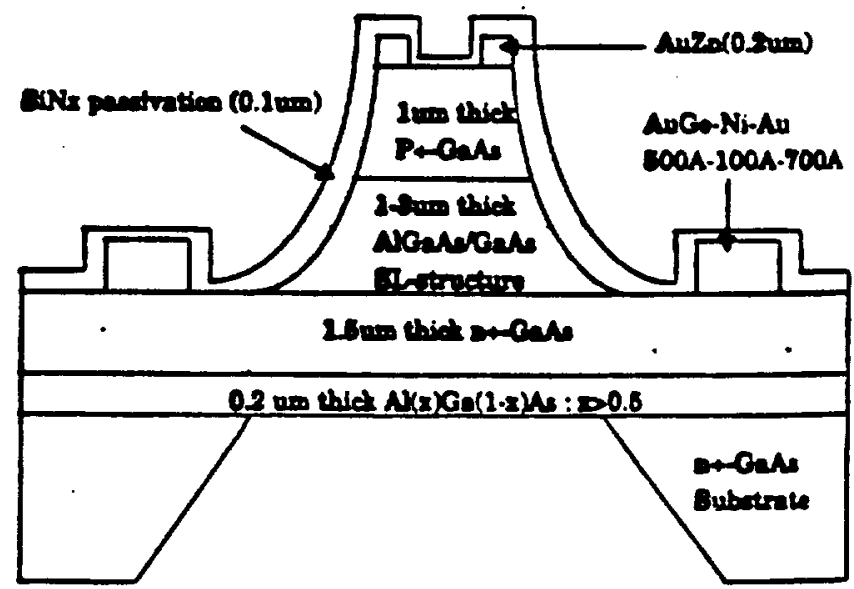

Figure 1 - Cross section of AlGals/GaAs MQW APD. 
The devices were fabricated on $2 \times 10^{-4} \mathrm{~cm}^{2}$ mesa structures with an active diameter in the range of 75 $1.30 \mathrm{\mu m}$ using andard photolithography techniques [9]. Since both $p$ and $n$ layers can be illuminated by remov. ing the substrates, the device configuration allows for electron or bole injection [10]. A $\mathrm{SiN}_{2}$ passivation coating suppresses surface leakage current and provides the devices with very low dark currents.

\subsection{Test Conditions}

High tempenture stonge tests and acolerated life tests were performed on four different devices with a constant reverse current of $10 \mu \mathrm{A}$ for 200 hours at three different ambient tempenture levels: 100, 150 and $200^{\circ} \mathrm{C}$. These conditions are summarized in Table 1. The accelerated life tests measured the failure nite under etressful conditions (i.e. - a reverse bias voltage of approximately $7.9 \mathrm{~V}$ ), the failure activation energy for the devices, and the average device lifetime. It was assumed that the temperature dependence of the failure rate $(R)$ obeys the following Arthenius law:

$$
R=R_{0} * \exp \left(-E_{\Omega} / k T\right)
$$

where $R_{0}$ is a temperature-independent pre exponential failure acceleration factor, $E_{\mathrm{a}}$ is the activation energy, $T$ is the absolute temperature, and $k$ is Boltumann's constant. During these tests, dark current and breakdown voluge were measured at room tempenture $\left(25^{\circ} \mathrm{C}\right)$. The breakdown voluge was defined from the device I$\checkmark$ curve using the tangential line method. Typical breakdown voltages for these devices were in the range of 7.5.9 V. The APDs were classified as failing when the dark currents at room temperature and $90 \%$ of the breakdown voltage exceeded $1 \mu \mathrm{A}$.

Table 1: Llfe Test Conditions

\begin{tabular}{|c|c|c|c|}
\hline Temperanure & Current & Samples & Time \\
\hline $100^{\circ} \mathrm{C}$ & $10 \mu \mathrm{A}$ & 4 & $200 \mathrm{hrs}$ \\
$150^{\circ} \mathrm{C}$ & $10 \mu \mathrm{A}$ & 4 & $200 \mathrm{hrs}$ \\
$200^{\circ} \mathrm{C}$ & $10 \mu \mathrm{A}$ & 4 & $200 \mathrm{hrs}$ \\
\hline
\end{tabular}

\subsection{Life Teat Results}

Several observations were made as a result of the accelerated life tests. Firsh dark current increases due to thermal overstress under bias were generilly found to be exponentially dependent on the time of exposure to the reverse-birs electric feld. This fact is shown Figure 9 , in which the dark current at a given reverse-bias volage increases significently as a function of aging time. Breakdown voluge, on the other hand, was shown to be nearly linearly dependent on stressing time (Figure 4).

Figure 5 shows the percent of cumulative failures for the AIGaAs/GaAs APDs verrus the lognomal projection of the device time-to-failure after accelerated life testing. In this representation, whough the eample size is small, the dats does indeed appear linear, which indicates that the failure mode is the wearout type, and

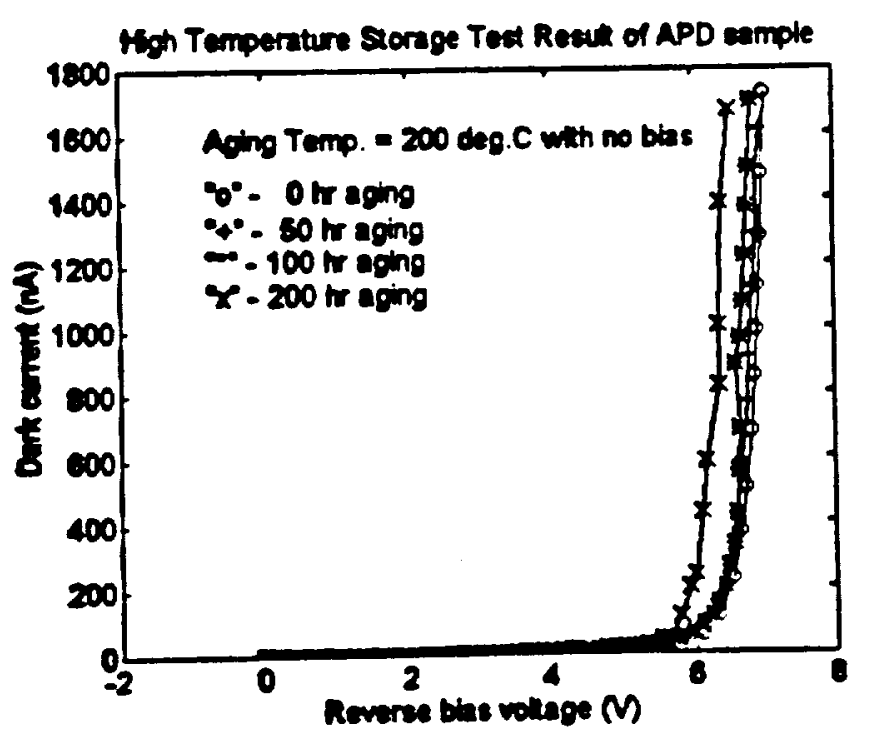

Figure 2 - Room-temperanure I-V curve of an APD sample afier 0,50, 100, and 200 hours of unbiased baling at $200^{\circ} \mathrm{C}$.

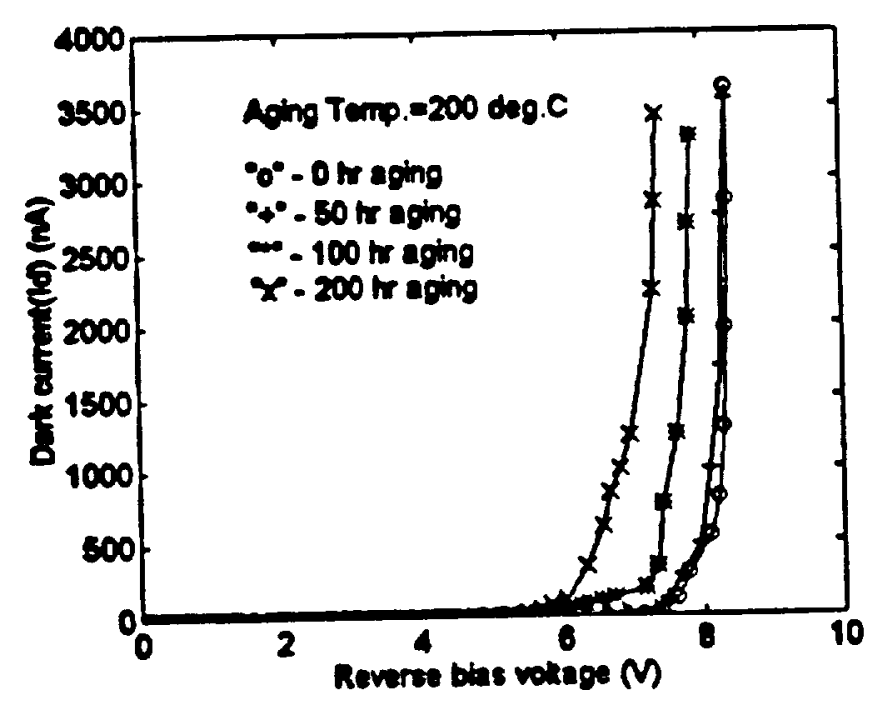

Figiure 3. Room-lemperanure I.V curve of an APD somple afier $0,50,100$, and 200 hours of aging under bias at $200^{\circ} \mathrm{C}$.

failures obey the lognormal distribution relatively well [S]. Median lifetimes at 100, 150, and $200^{\circ} \mathrm{C}$ are estimated to be 1400,210 , and 70 hours, respectively, with a standard deviation of 1.81. A few test points exhibit slight deviation from linear behavior, but this may be atributed to the smill sample size, as well as to infant mortality, eince the deviations typically occur at the 25\% level.

The Arthenius plof of median lifetimes as a function of reciprocal aging tempernture is thown in Figure 6. From this ploh the thermal activation energy of the device aging process is computed to be $0.46 \mathrm{eV}$ (3). Using this activation energy level, the median APD life. time for all 16 sumples under practical use conditions can be estimated to be $4.8 \times 10^{4}$ bours (approximately 5.5 years) at room tempernture, with a sundard devia- 


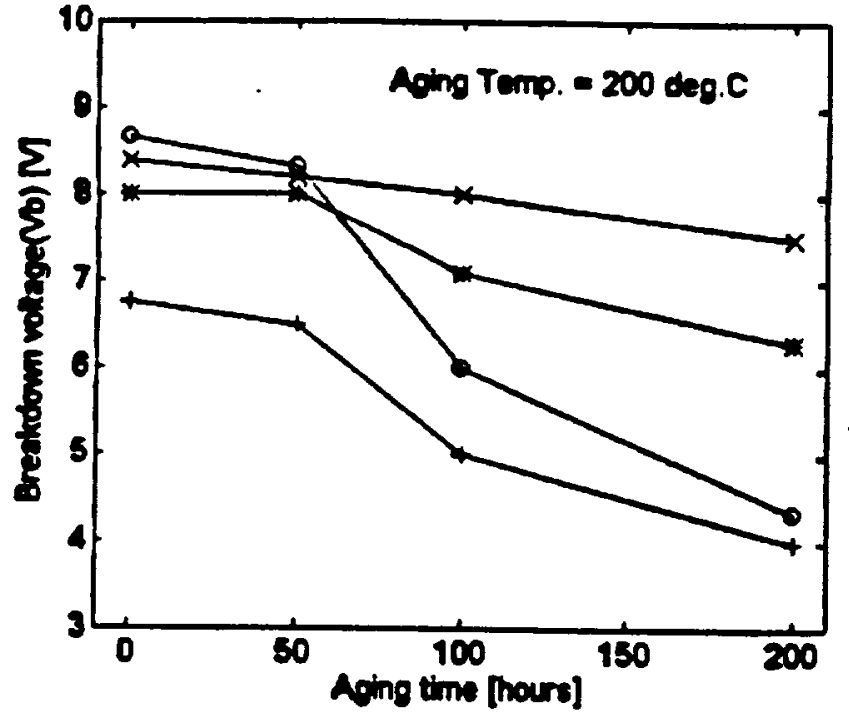

Figure 4 - Breakdown voltage variations afier accelerated life testing at $200^{\circ} \mathrm{C}$.

Cumutive Fallure [\%]

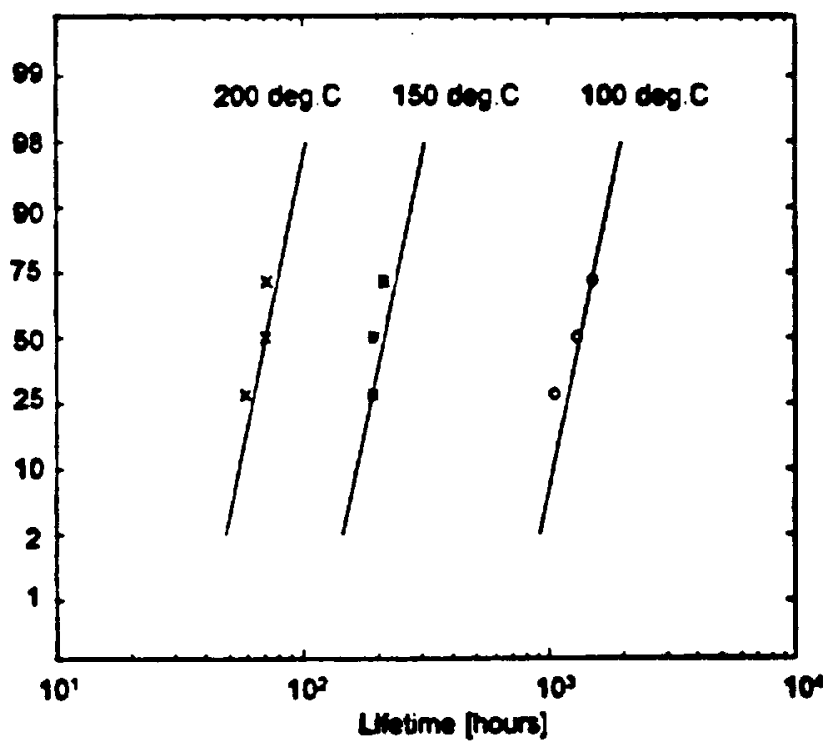

Figure 5 - Lognormal projection of time-ta-failure versus percent of cumulative failures for the AIGats/GaAs APDs afier life resting at 100, 150, and $200^{\circ} \mathrm{C}$.

tion of 113 hours.

Due to the lognormal degradation behavior of the APDs, the failure probability of each device as a function of time, $P(t)$, may be computed from the lognormal failure model by using the avenge device bifetime ( $\mu$ ) and its standard deviation (o) as [4]:

$$
P(t)=\frac{1}{\sigma \sqrt{2 \pi}} \int_{0}^{1} \frac{1}{t} \exp \left[-\frac{(\ln t-\mu)^{2}}{2 \sigma^{2}}\right] d t
$$

Along with Figure $S$, this expression provides a quantitative method of evaluating the likelihood of failure for

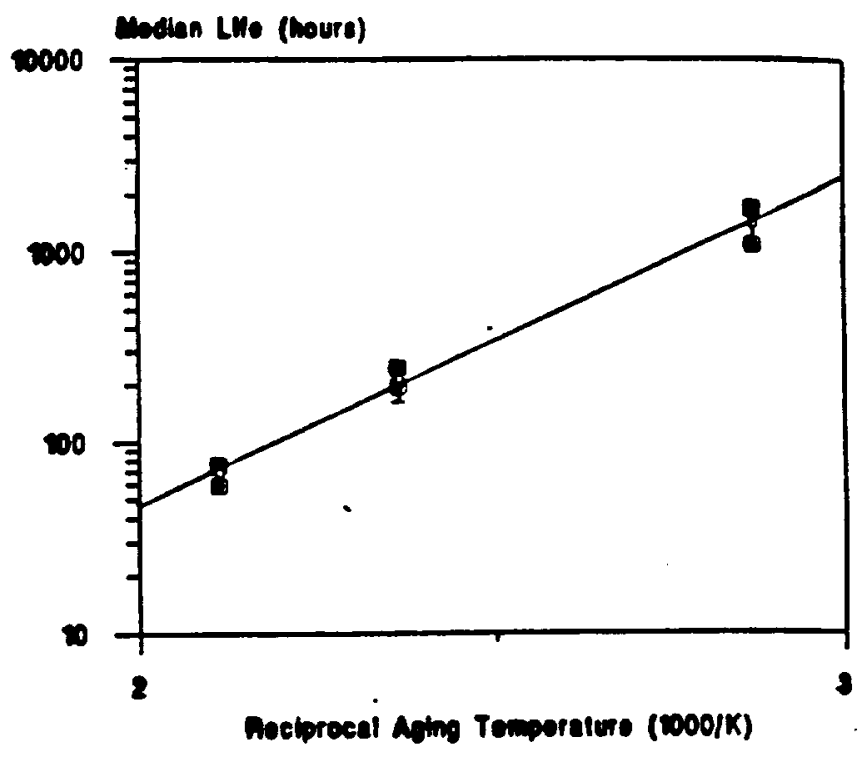

Figure 6 - Arrhenius plot of median device lifetimes as a function of reciprocal aging semperano.

a given device as a function of its age.

\subsection{Fallure Amalydis and Discuseion}

Failure analysis on the thermally aressed devices was carried out using scanning electron microscopy (SEM) and the electron-beam thduced current (EBIC) method [7]. Prior to this anlyris, two possible causes for dark current increases were hypothesized: 1) the presence of contaminents in passivating nitrides at the junction; or 2) the degradation of the surface due to thermil and electrical overstress on the interface cuus. ing in increase of the curface component of datk current [11]. Figure 7 shows an SEM image of a dev. ice prior to life cesting.

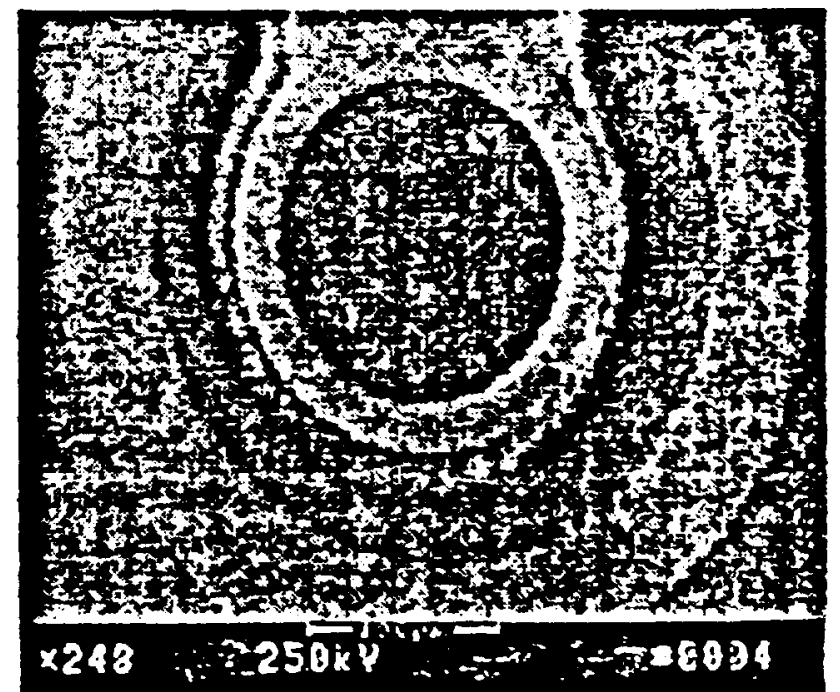

Figure 7 - SEM inage of GaAs MQW APD bfore occelerated life sesting.

From SEM and EBIC aniysis of the degnded 
amples, it was determined that the dark current increase was most likely due to the presence of ionic impurities or contamination in the silicon nitride pas. sivation layer at the junction perimeter that generntes a leakage path shorting the junction under the effect of electric field. This leakage is associated with bowrcsistance paths for carriers that consequently provide a mechenism for an increase in dat cournem. This hypothesis is supporred by the fact that unbiased baking of the APD samples resulted in significantly less degndation, which is demonstrated by a comparison of Figures 2 and 3.

An example of surface contamination which causes a local leakage path shorting the pn junction appears in Figure 8. A cormmon contaminant for silicon nitride passivating films is ionic codium [12]. Efforts are presently underway to experimentally identify of the contaminant in this case. It has been auggested that these type of defects occur at methl-rich precipitates, some of which oceur at crystal dislocations. The eause of the eradual reduction in breakdown voluge, on the other hand, is not known explicitly, but presumably involves the feld-assisted and temperaure-assisted drift of some impurity species or defects to localized sites in the pn junction.

\subsection{Conclusion}

Accelerated life tests of doped-barrier AlGaAs/GaAs MQW APDs were performed from the viewpoint of evaluating long-term reliability. From the life test results, the activation energy of the degradation mechanism was determined to be approximately 0.46 $\mathrm{eV}$ and the median lifetime of these devices was estimated to be $4.8 \times 10^{4}$ hours at room tempernure. In addition, the failure probability of the devices was $c 0 \mathrm{~m}$ puted from the lognormal failure model by using the avenge lifetime and the standard deviation of that lifelime as parameters. Subsequent failure analysis using the SEM and EBIC methods clarified that the degndation due to dark cument increase was brought about by the presence of ionic impurities or contamination in the passivation layer at the junction perimeter that genernte a leskage path and shorts the junction under the effect of electric field.

In the near future, these life test results will be compared to other APD structures, including undoped and doped-well devices. These structures are all being considered as candidates for the high-definition system innge capture application. The purpose of this comparison will be wo determine the advantages and disadvantages of each device structure in terms of relia. bility.

\section{Acknowledgement}

The authors would like to thank NASA (contract D. NAGW-2753) for rupport of this research. We are also grateful to Alan Doolitale for his aid in performing EBIC experiments and for many helpful diecussions.
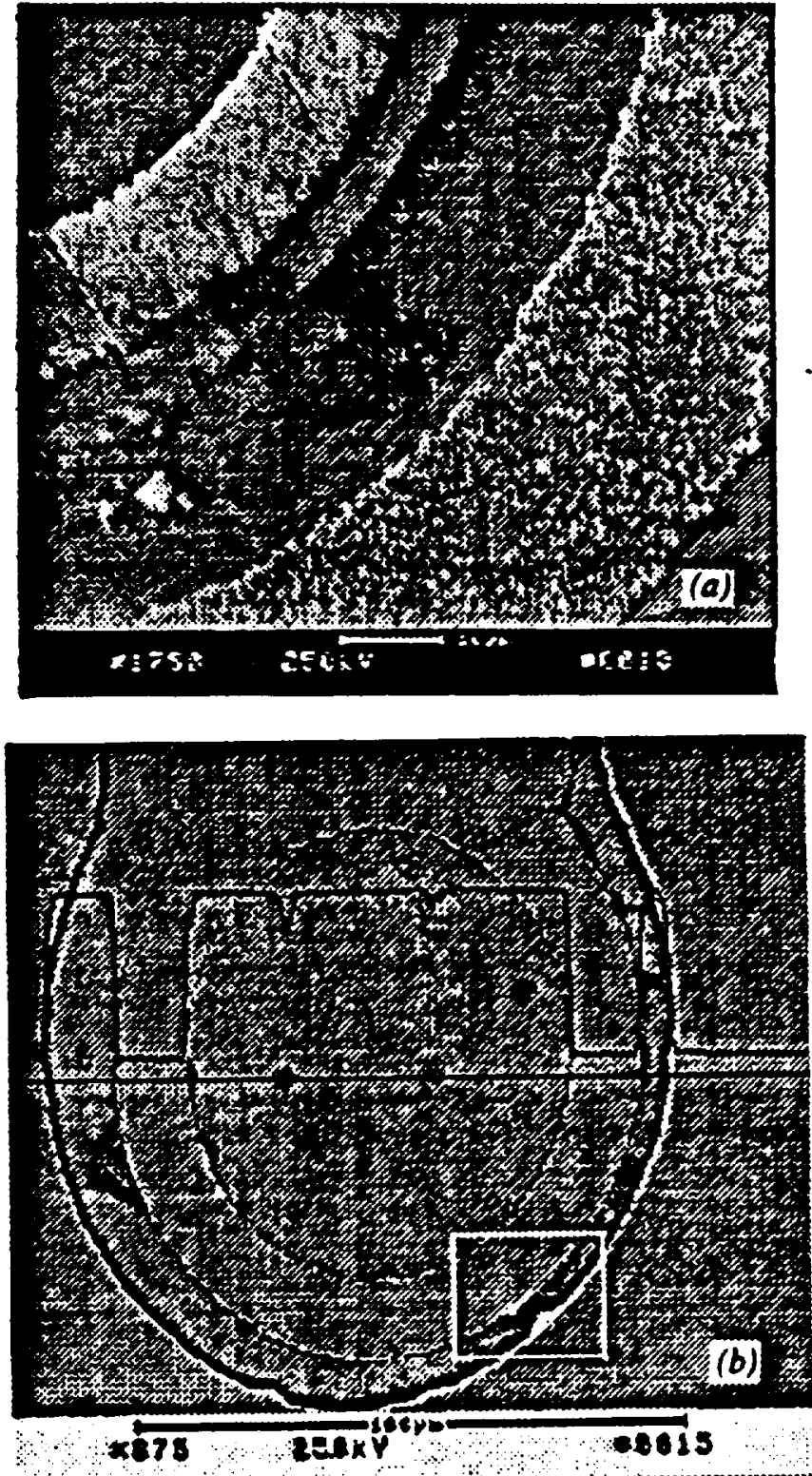

Figure 8 - (a) SEM and (b) EBIC innges of GaAs ATOW APD ofier accelerated life testing at $200^{\circ} \mathrm{C}$.

\section{References}

[1] K. Bremran, Theory of the Doped Quantum Well Superlatice APD: A New Solid State Photomultiplier," IEEE J. Quan. Elec., vol. QE-22, pp. 1999. 2016, 1986.

(2) M. Teich, K. Matsuo, and B. Sulh, Excess Noise Factors for Conventional and Superhutice Avalunche Photodiodes and Photomultiplier Tubes," IEEE J. Quan. Elec., vol. QE-22, pp. 1184-1193, 1987.

[3] W. Joyec, K. Liou, F. Nash, P. Bossard, and R. Hertmin, "Methodology of Accelernted Aging", AT\&T Tech. Jownal, vol. 64, Do. 3, Pp. 717-764, March, 1985. 
[4] F. Nash, Estimating Device Reliability, Boston: Kluwer, 1993.

[5] H. Sudo and M. Suzuki, "Surface Degradation Mechanism of InP/InGaAs APDs," J. Lighrwave Tect., vol. 6, no. 10, pp. 1496-1501, Oct. 1988.

[6] J. Bauer and R. Trommer, "Long-term Operation of Planar InGaAs/InP p-i-n Photodiodes," IEEE Trans. Elec. Dev., vol. 35, no. 12, pp. 2349-2353, Dec., 1988.

[7] E. Pollino, Microelectronic Reliability, vol. 2, Boston: Artech House, 1989.

[8] P. Aristin, A. Tonbi, A. Garrison, H. Harris and C. Summers, "Evaluation of New Multiple Quantum Well Avalanche Photodiode Structures: The MOW, The Doped Barrier and Doped Quantum Well," Inst. Phys. Corf. Series, no. 120, 1991.

[9] P. Aristin, A. Torabi, A. Ganison, H. Hamis and C. Summers, "New Doped Multiple Quantum Well Avalanche Photodiode: The Doped Barrier Al $0.35 / \mathrm{Ga}_{0.65} / \mathrm{As} / \mathrm{G} 2 \mathrm{As}$ Multiple Quantum Well Avalanche Photodiode", Appl. Phys. Lett., vol. 60, no. 1, pp. 85-87, Jan., 1992.
[10]A. Tornbi, K. Brennan, and C. Summers, "Grom and Application of Superhattices and Quantu Wells". SPIE Proc., vol. 835, pp. 90-94, 1988.

[11]Y. Kuhan, H. Tenuchi and H. Nishizawa, Reli: bility of InGaAs/InP Long-Wavelength p-i-n Photc diodes Passivated with Polyimide Thin Film", Jow nal of Lighrwave Tech., vol. LT4, no. 7, pp. 93: 936, July, 1986.

[12]S. Wolf and R. Tauber, Silicon Processing for th VLSI Era, Sunset Beach, CA: Lattice Press, 1986.

[13]H. Sudo, Y. Nakeno and G. Iwane, "Reliability c Germanium Avalanche Photodiodes for Optic Transmission Systems", IEEE Tran. Elec. Det vol. ED-33, no. 1. pp. 98-103, Jan., 1986

[14]C. Skrimshire, J. Far, D. Sloan, M. Robertson, ] Putland, J. Stokoe and R. Sutherland, Reliabilit of Mesa and Planar InGaAs PIN Photodiodes", IE Proc., vol. 137, no. 1, pp. 74-78, Feb., 1990. 